NASA Technical Memorandum 106617

AIAA-94-2757

$2 P$

\title{
The Prediction of Nozzle Performance and Heat Transfer in Hydrogen/Oxygen Rocket Engines with Transpiration Cooling, Film Cooling, and High Area Ratios
}

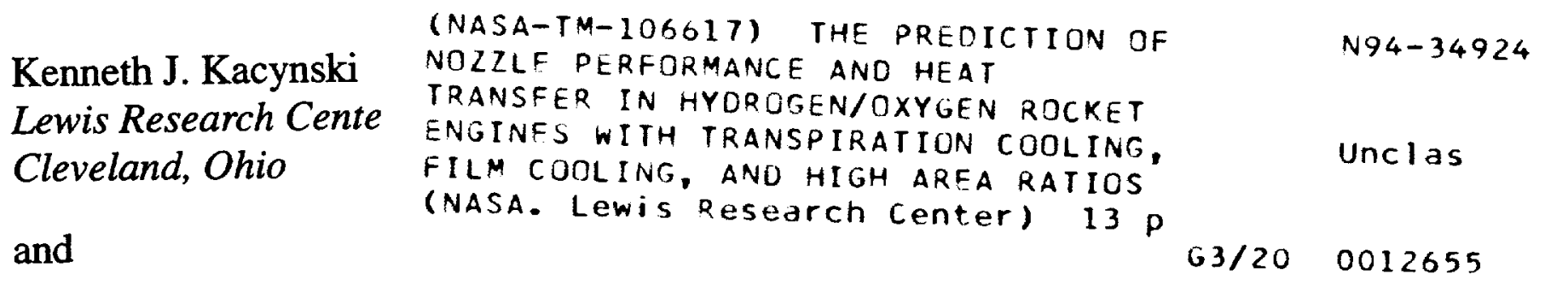

Joe D. Hoffman

Purdue University

West Lafayette, Indiana

Prepared for the

30th Joint Propulsion Conference cosponsored by AIAA, ASME, SAE, and ASEE Indianapolis, Indiana, June 27-29, 1994

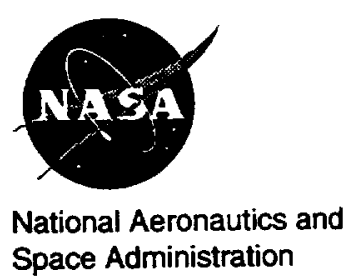

Space Administration 


\author{
Kenneth J. Kacynski* \\ NASA Lewis Research Center \\ Cleveland, $\mathrm{OH}$
}

Joe D. Hoffman**

Purdue University

West Lafayette, $\mathbb{N}$

\begin{abstract}
An advanced engineering computational model has been developed to aid in the analysis of chemical rocket engines. The complete multispecies, chemically reacting and diffusing Navier-Stokes equations are modelled, including the Soret thermal diffusion and Dufour energy transfer terms. Demonstration cases are presented for a 1030:1 area ratio nozzle, a $25 \mathrm{lbf}$ film-cooled nozzle, and a transpiration-cooled plug-and-spool rocket engine. The results indicate that the thrust coefficient predictions of the 1030:1 nozzle and the film-cooled nozzle are within 0.2 to 0.5 percent, respectively, of experimental measurements. Further, the model's predictions agree very well with the heat transfer measurements made in all of the nozzle test cases. It is demonstrated that thermal diffusion has a significant effect on the predicted mass fraction of hydrogen along the wall of the nozzle and was shown to represent a significant fraction of the diffusion fluxes occurring in the transpiration-cooled rocket engine.
\end{abstract}

\section{Nomenclature}

$\mathrm{A}_{\mathrm{ij}} \quad$ Ordinary mass diffusion coefficient

$C_{F} \quad$ Nozzle vacuum thrust coefficient

$c^{*} \quad$ Characteristic velocity, $\mathrm{ft} / \mathrm{sec}$

$D_{i}^{T} \quad$ Thermal diffusion coefficient of species $i$

$h_{i} \quad$ Enthalpy of species $i$

$j_{i} \quad$ Diffusion mass flux of species $i$

$j_{i}^{t} \quad$ Turbulent mass flux of species $i$

$I_{\text {sp }} \quad$ Nozzle specific impulse, lbf-sec/lbm

k Effective thermal conductivity

q Heat flux

P Fluid static pressure

$P_{0} \quad$ Nozzle chamber stagnation pressure

T Fluid temperature

$\wp_{\mathrm{iM}}^{\mathrm{t}}$ Turbulent diffusion coefficient

$\varsigma_{i j} \quad$ Dufour energy transfer coefficient

$\omega_{i} \quad$ Mass fraction of species $i$

* Member AIAA

**Professor, Mechanical Engineering Department Associate Fellow, AIAA
Introduction

The computation of rocket-nozzle performance is of critical importance to the rocket-engine industry. Often, the rocket engine manufacturer needs to compare various engine operating systems before deciding on a specific configuration. Two items that are of critical importance are nozzle performance and nozzle heat transfer characteristics. Often these two parameters are interrelated. This is most apparent in cases involving transpiration cooling or film cooling. Under these circumstances, the actively cooled boundary layer serves to thermally (and perhaps chemically) protect the nozzle wall from the exhaust gasses of the core flowfield. In such conditions, the coolant allows the rocket engine to operate at conditions otherwise not attainable, such as higher chamber pressures or lower thrust levels. The engine designer must then ascertain whether the increased operating pressure or lower thrust level is worth the decreased performance of the engine because of active cooling. Consequently, a need exists for a comprehensive rocket nozzle prediction capability that can accurately determine performance and heat transfer characteristics for design and trade-off studies.

A different need exists for individuals interested in improving rocket nozzle performance predictions and modelling. Here, it is important for the individual to ascertain the primary limitations of the prediction technique. A model which would include as many of the potential performance and heat transfer effects as possible and also allow the examination of individual effects, such as species diffusion or chemical kinetics, would be most desirable, with the additional constraint that the solution should be reasonably insensitive to the computational grid employed for the analysis.

\section{Bresent Study}

Modelling of the multispecies rocket-nozzle flowfield equations was accomplished by modifying the compressible Navier-Stokes code, Proteus. ${ }^{1-3}$ The Proteus code included the ability to model the time-averaged NavierStokes equations for a single-species perfect gas (constant $\gamma$ ). For a fluid with the properties of air, the Proteus code also included the ability to model a temperature-dependant specific heat, thermal conductivity, and viscosity.

In the present study, inclusion of the multiple species advection, production (i.e., chemical kinetics), and diffusion terms, with full coupling in the total energy equation, was developed. Further, species and heat transfer processes by diffusion were modelled with consideration 
given to the interrelation between species and heat transfer mechanisms (i.e., the Soret and Dufour effects).

The code was further enhanced by the inclusion of the following boundary conditions:

- Characteristic equations at the boundaries;

- Mixed subsonic-supersonic exit conditions;

- Coupled temperature/mass flow wall conditions.

The resulting fluid-flow model that incorporates all of the above modifications to the Proteus code was called Tethys.

\section{Governing Equations}

The multispecies Navier-Stokes equations governing the flow of a fluid are similar to their single-species counterpart, with the exception that additional species-transfer equations must be solved. The species-transfer equations contain advective, source (due to chemical reactions), and diffusive components. The governing equations can be found in Reference 4 and, for brevity, are not repeated here. A unique aspect of multispecies fluid flow is that the constitutive equations governing the flow of heat and species transfer are significantly more complicated than those of a single-species gas.

The constitutive equations of heat transfer are complicated by the presence of multi-species interactions as heat can transfer diffusively by means of thermal conduction, interdiffusion, and Dufour heat transfer, as shown below:

$$
q=-k \nabla T+\sum_{i=1}^{n} h_{i}\left(j_{i}+j_{i}^{t}\right)+\sum_{i=1 j=1}^{n} \sum_{i j}^{n} \varsigma_{i j}\left[\frac{j_{i}}{\omega_{i}}-\frac{j_{j}}{\omega_{j}}\right]
$$

Conduction Interdiffusion Dufour heat transfer

The transport of species can be the result of ordinary diffusion and thermal (i.e., Soret) diffusion, with the additional complication that the Boussinesq approximation for turbulent mass transfer in not completely analogous to its laminar counterpart, as illustrated in the following equation:

$$
\begin{aligned}
& j_{i}+j_{i}^{l}=\sum_{j=1}^{n-1} A_{i j} \nabla \omega_{j}-\frac{D_{i}^{T}}{T} \nabla T-\wp_{i M}^{t} \nabla \omega_{i} \\
& \text { Ordinary Thermal Turbulent } \\
& \text { diffusion diffusion diffusion }
\end{aligned}
$$

\section{Generalized Coordinate Transformation}

A transformed cylindrical coordinate system was used for accurate boundary description and to vary the resolution of the computational grid. The specific details of the transformation technique employed can be found in Reference 5 , with the unique details of the transformation method outlined as follows:

- All radius terms contained within axial derivatives are evaluated as spacial averages;

- The differencing of the metrics are never beyond the boundary at which a dependent variable has been evaluated;

- The pressure gradient in the radial momentum equation is described in weak conservation form.

The reformulation using the above guidelines results in discretized expressions that are both more robust and more accurate, based on fundamental flow situations, than the method used in the Proteus code.

\section{Demonstration Tests}

The application of the reacting, multispecies diffusing, discretized flowfield equations will be shown for three unique hydrogen/oxygen rocket engines that were tested at the NASA LeRC rocket-engine test facilities. First, a high area ratio (1030:1) rocket nozzle was analyzed and discussed in detail. The application of such a nozzle has been envisioned to include orbital transfer, lunar, and planetary missions. An extensive experimental database exists that includes performance, heat flux, and static wall pressure measurements. A second hydrogen-oxygen rocket case that will be presented is a film-cooled, low thrust ( $25 \mathrm{lbf})$ engine that has been proposed for satellite thruster applications and for the orbital maintenance of a man-tended space station. The uniqueness of this engine concept was the extensive film cooling with hydrogen and operation at an overall stoichiometric mixture ratio while having an oxygen/hydrogen mixture ratio of 20 in the core. Static wall pressures and global heat transfer and engine performance data are available for comparative purposes. The final configuration examined is a transpiration-cooled plug-and-spool rocket engine. The uniqueness of this configuration was that a discrete section of the rocket has transpiration hydrogen coolant along the wall.

\section{LeRC 1030:1 High Area Ratio Nozzle}

A high area ratio hydrogen/oxygen rocket nozzle (Figure 1) was tested at the NASA Lewis Research Center. ${ }^{6-8}$ Gaseous hydrogen and oxygen were injected into a combustion chamber that had a subsonic area ratio of 4.22:1. In the chamber, the propellants were burned to near completion, with the combustion efficiencies in each test ranging from 93 to 99 percent.

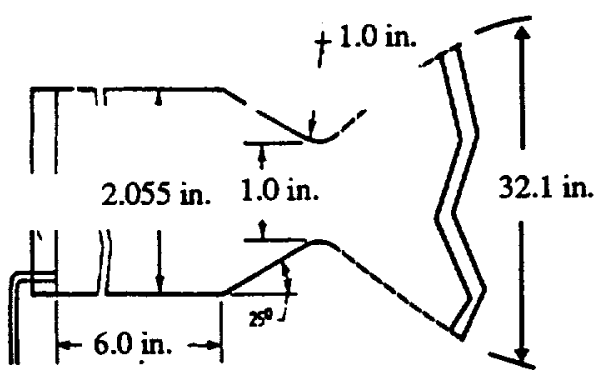

Fig. 1. LeRC 1030:1 nozzle dimensions.

\section{Analvtical assumptions}

Four different nozzle cases, with various assumptions, 
were considered and are shown in the following table. The analysis cases varied from a chemically frozen, inviscid case, to a chemically reacting, multi-species diffusion case.

Table 1. Analysis methods used for the 1030.1 nozzle.

\begin{tabular}{|l|c|c|c|c|}
\hline \multicolumn{1}{|c|}{ Analysis } & Case 1 & Case 2 & Case 3 & Case 4 \\
\hline \hline Chemical kinetics & No & No & Yes & Yes \\
\hline Viscous flow & No & Yes & Yes & Yes \\
\hline Ordinary diffusion & No & No & Yes & Yes \\
\hline Thermal diffusion & No & No & No & Yes \\
\hline $\begin{array}{l}\text { Interdiffusion } \\
\text { heat transfer }\end{array}$ & No & No & Yes & Yes \\
\hline Dufour transfer & No & No & No & Yes \\
\hline
\end{tabular}

For analytical comparison, several important assumptions were made concerning the environment under which the rocket nozzle performed. The major assumptions regarding the flowfield included complete mixing at the nozzle inlet, the magnitude of the ambient pressure at the nozzle exit, and laminar flow throughout the nozzle.

The flow at the inlet of the nozzle section was assumed to be fully mixed and in chemical equilibrium, leaving the lack of complete mixing as a 'correction factor' to be applied to the engine performance measurements.

The ambient pressure at the nozzle exit can be an important parameter as the nozzle could experience some level of 'boundary layer feedback' where the subsonic flow region of the boundary layer is affected by the pressure at which the nozzle exhausts to. In turm, this can affect the pressure on the nozzle wall for some distance upstream of the nozzle exit plane. Since the nearest static pressure tap on the nozzle was located 2.7 inches from the exit, a small extrapolation ( $4.1 \%$ ), using the interior nozzle static pressures was required to establish the nozzle ambient pressure. It should be noted that the ambient pressure applied in this analysis was $30 \%$ lower than the capsule pressure, thus indicating that the nozzle was somewhat overexpanded.

The nozzle flow was assumed to be laminar throughout the flowfield. Extensive studies and correlation with experimental and analytical predictions indicate that the rapid acceleration of the exhaust gasses in the throat region of the nozzle 'laminarizes' the flowfield. ${ }^{7,9}$ Additional studies have indicated that the laminarized profile was stable throughout the supersonic region of the nozzle. ${ }^{10}$ The transonic and supersonic region of the nozzle was the area of greatest concern, as this was the region where the growth of the boundary layer was rapid and the divergent region of the nozzle was also the location where all of the experimental wall measurements were made. Consequently, the assumption of laminar flow throughout the nozzle was reasonably justified.

Boundary conditions employed in the analysis used parameters measured in the experimental program such as the chamber pressure and chamber mixture ratio, and the wall temperature. The nozzle ambient pressure was used as a boundary condition when the normalized contravarient velocity was less than the speed of sound. At the nozzle inlet, the flow was assumed to be in chemical equilibrium.

Constant reference-plane characteristic relations were used at all boundaries. At the inlet and exit, the characteristic relations included viscous, chemically reacting terms. Along the nozzle centerline and wall, a chemically-frozen, inviscid characteristic relation was used. When applied to a no-slip wall, the characteristic equation reduces (at steady state, and in the limit as the grid spacing reduces to zero) to the assumption that the normal pressure gradient is equal to zero. Additional boundary conditions along the centerline (and along the wall in the inviscid analysis) included the assumption that the gradient in enthalpy and entropy were zero.

\section{Computational Grid Used for Analytical Study}

In Figure 2, the $91 \times 51$ numerical grid used for the viscous analysis of the 1030:1 nozzle is shown. A slightly more coarse grid was used in the inviscid analysis case but was essentially indiscernible to casual visual inspection, and is not presented.

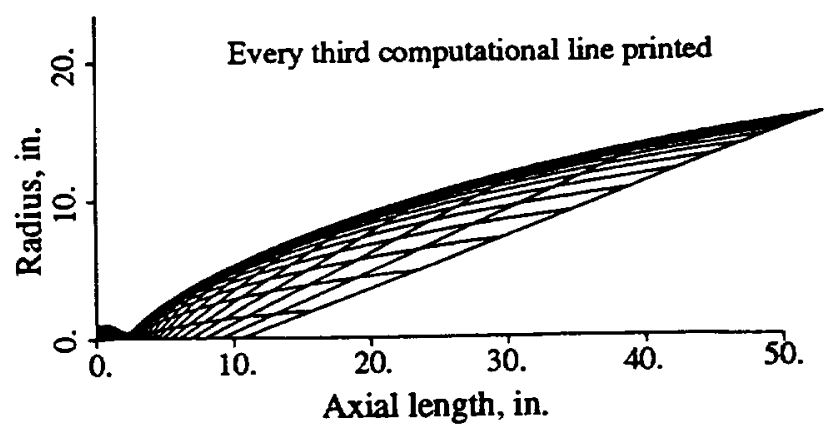

Fig. 2. Computational grid used for LeRC 1030:1 nozzle.

The most unique aspect of the computational grid shown in Figure 2 is that the centerline length is significantly shorter than the nozzle length. This 'centerline coring' of the computational grid takes advantage of the fact that, in supersonic flow, information can only propagate within a discrete region (the domain of influence) and computer tests run with coarser grids indicated that the grid shown in Figure 2 was well downstream of the domain of influence of the supersonic core on the nozzle wall. The net result of this 'coring' in the centerline region was that it allowed significantly more grid points to lie in a physical location where they would be of use to resolve the flowfield and the conditions that exist along the wall. 


\section{Mach Number Contour Predictions}

In Figure 3 to 6, Mach number contours as predicted for Case 1 and 4 are shown, with the other two viscous test cases having profiles qualitatively similar to those presented in Figures 5 and 6. Close inspection of Figure 3 reveals that the flow near the wall of the nozzle in the supersonic region undergoes a large amount of compressive turning. The result of the compressive turning is that the Mach number contours are nearly parallel to the wall.

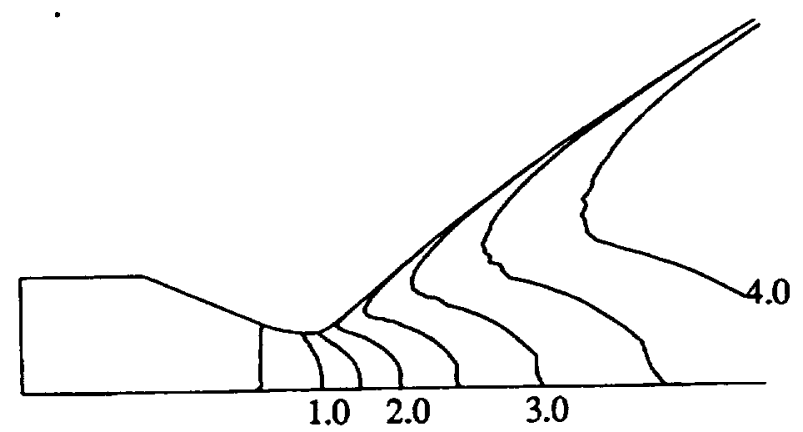

Fig. 3. Throat region Mach number predictions, Case 1.

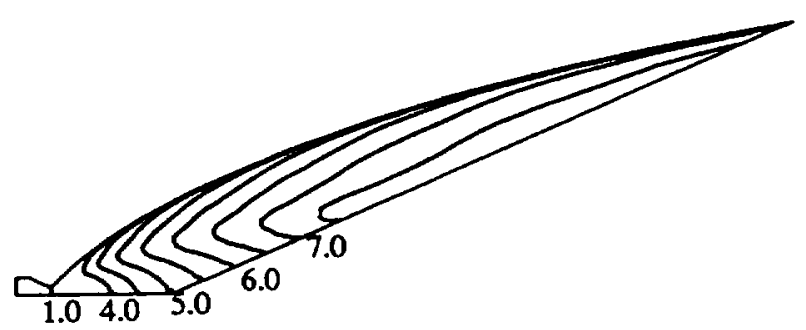

Fig. 4. Predicted Mach number contours, Case 1.

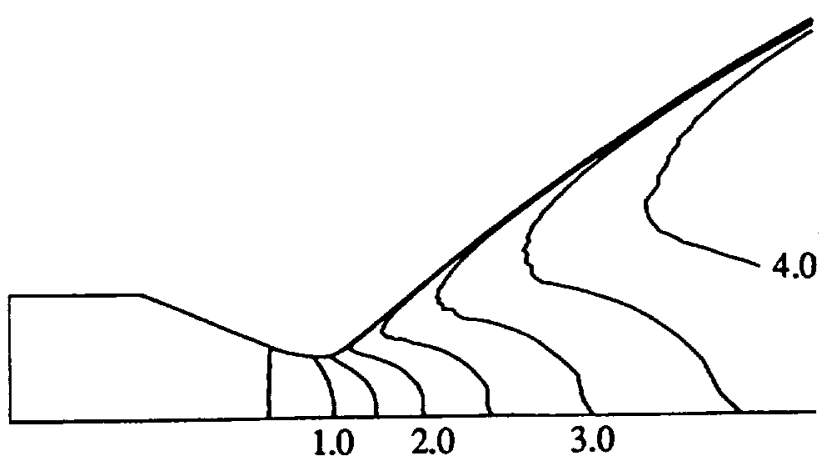

Fig. 5. Throat region Mach number predictions, Case 4.

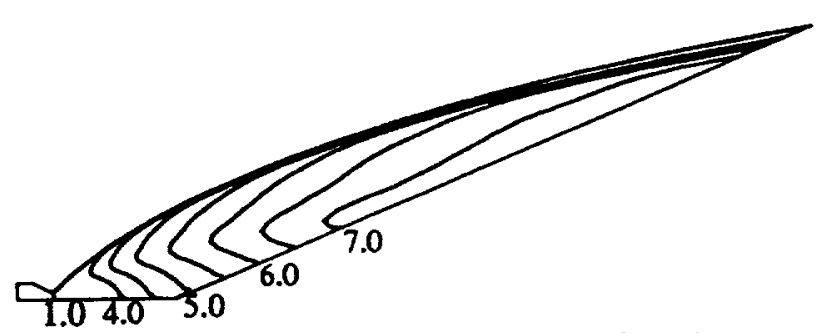

Fig. 6. Predicted Mach number contours, Case 4.

It is also observed that the centerline boundaries appear to over dampen the Mach number contours in the supersonic regions of the flow. This may be because of the computational grid employed for the analysis as the constant $\xi$ lines go from left -to-right as the physical location goes from the center to the wall, as illustrated in Figure 2. However, in supersonic flow, the centerline can only be influenced by conditions existing within its Mach cone, which is in the leftward direction. As a result, any relation developed between a centerline point and an interior point located outside of the domain of dependance is physically unrealistic. In the computational grid employed in this analysis, this aspect is far more pronounced than in an analysis that employs orthogonal grid structures at a centerline, although even an orthogonal grid violates the principle of the domain of dependance. Fortunately, the analysis of the centerline region appears excellent in the transonic/ slightly supersonic region and the error that occurs near the end of the centerline region will have little effect on the wall conditions.

\section{Wall Static Pressure and Heat Elux Comparison}

In Figure 7 and 8 a comparison for Case 4 of the predicted and measured pressure and heat flux distributions in the supersonic region of the nozzle (the only region where measurements were made) are shown. The predictions and measurements are in excellent agreement.

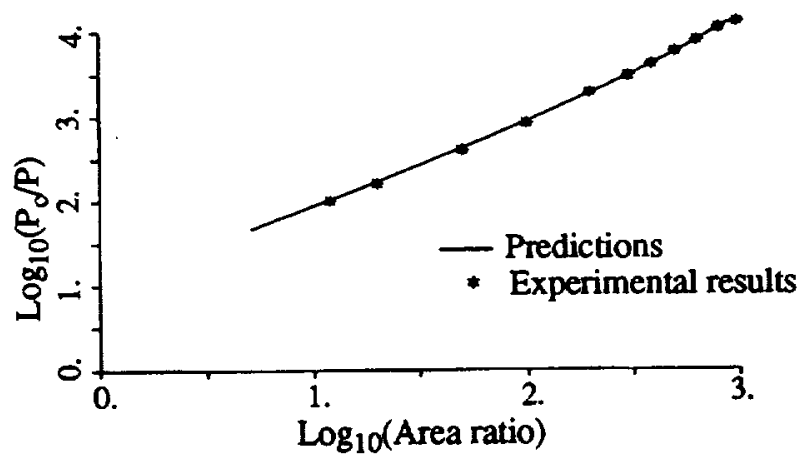

Fig. 7. Comparison of measured and predicted wall static pressures.

It is especially noteworthy that the 'kink' in the slope at the last three points of wall pressure measurements shown was correctly predicted.

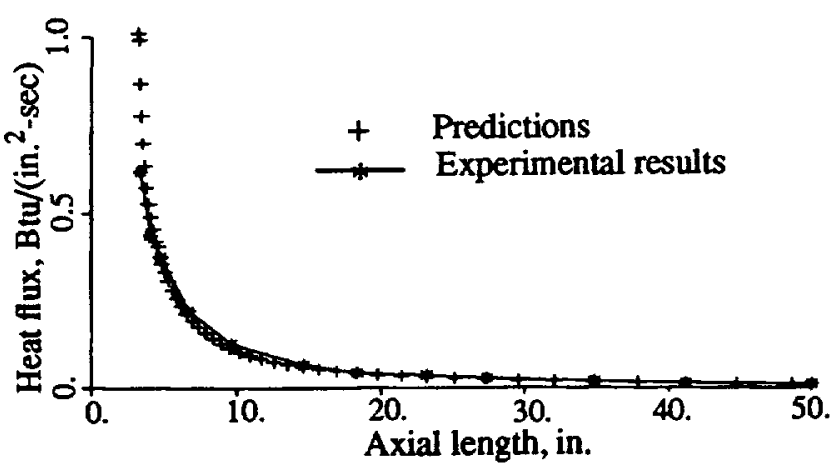

Fig. 8. Comparison of measured and predicted heat fuxes.

The heat-flux predictions are slightly higher than experimental measurements in the near throat region, fol- 
lowed by predictions that are slightly lower than experimental measurements. Excellent agreement of experimental and predicted heat fluxes occurs from about 20 in. axial distance to the exit of the nozzle.

\section{Prediction of Hydrogen Mass Fraction Along the Wall}

In Figure 9 the mass fraction distribution of diatomic hydrogen predicted to occur along the wall of the LeRC 1030:1 nozzle is presented for all of the viscous nozzle analysis cases performed. As expected, the concentration of hydrogen along the nozzle wall for the frozen analysis (Case 2) was constant throughout the length of the nozzle. On the other hand, the mass fraction of hydrogen for the chemically-reacting, ordinary-diffusion case (Case 3) increases slightly at the inlet due to the recombination of monatomic hydrogen, and then decays towards the fullymixed, frozen mass fraction as the fluid undergoes a combination of species mixing and freezing of the chemicalreaction mechanisms. The most pronounced difference in the predictions of hydrogen mass fraction occurs in Case 4 , where Soret mass transfer was considered. In this case the hydrogen mass fraction immediately drops to one-half its inlet value, then slowly increases as the boundary layer thickens in the combustion chamber. The hydrogen mass fraction reaches a local maximum near the throat where the strength of the Soret mass transfer term was weak from the presence of a modestly cooled, ceramic coated wall. The hydrogen mass fraction then decays to a local minimum as the Soret mass transfer term increases from the rapidly decreasing wall temperatures in this region. Finally, as the ceramic-coated section ends and the heat fluxes diminish, the hydrogen mass fraction again increases as the temperature gradients at the wall decrease and the boundary layer thickens, essentially remixing the fluid. This partial-remixing process continues as the nozzle temperature gradient continues to decrease throughout the extent of the expansion region of the nozzle.

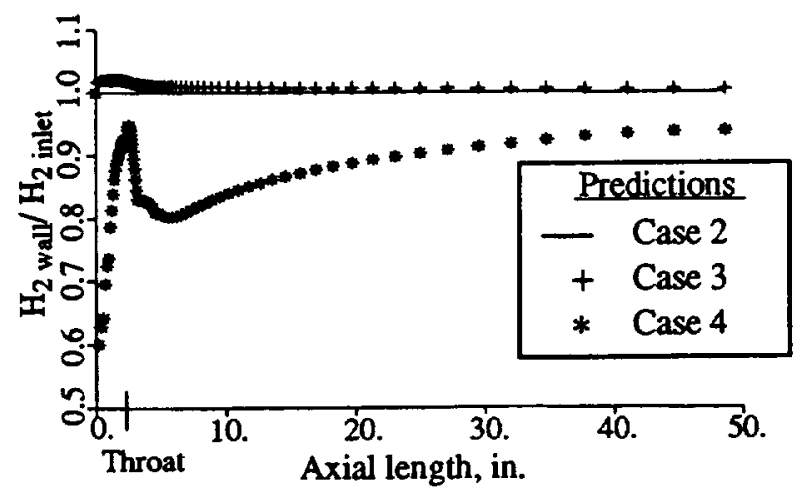

Fig. 9. Hydrogen wall mass fraction predictions.

\section{Performance Predictions}

A comparison of predicted performance parameters for the four numerical test cases analyzed is shown in Table 2. The procedure used to determine nozzle thrust and mass flow rate corresponds as nearly possible to that recommended in the JANNAF nozzle analysis procedure. $^{11}$ This method involved the numerical integration of the pressure forces and axial-momentum fiux across the throat of the nozzle, which in this case corresponded to the first grid line that extended into the divergent portion of the nozzle, and summing the pressure and drag forces along the divergent surface of the nozzle.

Table 2. Performance predictions for the 1030:1 nozzle.

\begin{tabular}{|c|c|c|c|c|}
\hline & Case 1 & Case 2 & Case 3 & Case 4 \\
\hline \hline$I_{\text {sp }}$ & 488.2 & 481.6 & 493.6 & 494.1 \\
\hline$C_{F}$ & 1.959 & 1.924 & 1.941 & 1.942 \\
\hline
\end{tabular}

Several conclusions can be drawn. The first is that chemical kinetics seems to have the largest single effect on nozzle performance, with the performance difference between the frozen and kinetic cases (Cases 2 and 3, respectively) being about $2.5 \%$, where the frozen case is lower. Examination of Cases 1 and 2 reveals that viscous effects account for approximately a $1.4 \%$ decrease in nozzle performance. The effects of multidiffusion mass and heat transfer, the difference between Case 3 and 4, account for a predicted increase in nozzle performance of $0.1 \%$.

\section{Comparison of Performance Predictions}

In Table 3, a comparison between the predictions made with Tethys, Case 4, and experimental measurements is shown along with previous performance predictions using other models, namely TDK and RPLUS. ${ }^{12,13}$ The TDK prediction method involves an inviscid (onedimensional/transonic/MOC)- boundary layer type of analysis with chemical kinetics in the inviscid region while RPLUS is a chemically reacting Navier-Stokes model which was executed using a $270 \times 60$ computational grid. The measured specific impulse has been corrected for incomplete mixing and/or combustion by the use of an inviscid, chemical-equilibrium correction factor.

A comparison of the predictions to the experimental measurements indicates that the Tethys flow model is in far better agreement with the experimental measurements than other computational models. Here it is seen that the predicted thrust coefficient and specific impulse from the Tethys model are about $2 \%$ closer to experimentally measured values than the other nozzle-prediction models.

Table 3. Performance comparisons for the 1030:1 nozzle.

\begin{tabular}{|c|c|c|c|c|}
\hline \multirow{2}{*}{} & \multirow{2}{*}{ Measured } & \multicolumn{3}{|c|}{ Predicted/Measured, \% } \\
\cline { 3 - 5 } & & Tethys & TDK & RPLUS \\
\hline \hline $\mathrm{C}_{\mathrm{F}}$ & 1.946 & -0.21 & -2.7 & -1.4 \\
\hline $\mathrm{I}_{\mathrm{sp}}$ & 495.6 & -0.30 & -2.8 & -3.7 \\
\hline
\end{tabular}

The differences between measured and predicted val- 
ues of thrust coefficient and the differences between the measured and predicted specific impulse should be nearly the same. The difference between the two values reflects the predicted value of the discharge coefficient of the nozzle. In the Tethys model, the predicted discharge coefficient is equal to 0.991 while the TDK and RPLUS models predict 0.99 and 0.977 , respectively. Consequently, the proximity to which the discharge coefficient of the nozzle is equal to unity lends additional credence to the accuracy of the Tethys code.

\section{$25 \mathrm{lbf}$ Film-Cooled Rocket Engine}

A low-pressure (75 psia), low-thrust (25 lbf) hydrogen/oxygen rocket engine was tested at the NASA LeRC as part of a nozzle contour evaluation program. ${ }^{14,15} \mathrm{~A}$ schematic of the nozzle geometry is shown in Figures 10 and 11. In Figure 10, a schematic of the nozzle geometry and test apparatus is shown. In Figure 12 a view of the film- cooling and injector apparatus is presented. From Figure 11, the hydrogen film acts as a wall jet, the hydrogen being injected along the surface of the nozzle, and initially separated from the core by a solid-walled sleeve.

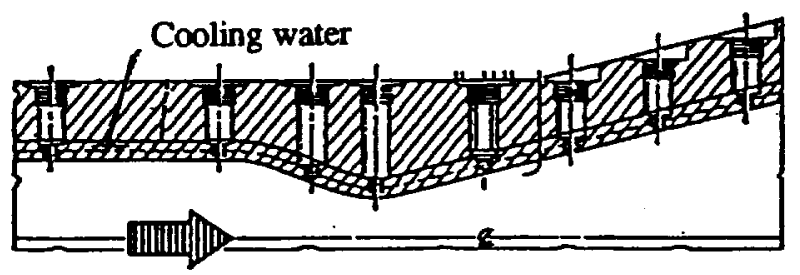

Fig. 10. Film cooled nozzle geometry.

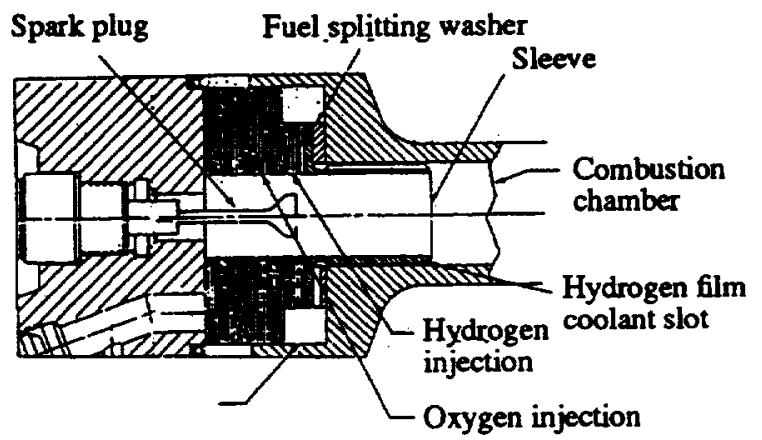

Fig. 11. Injector and film-cooled sleeve assembly.

\section{Computational Grid Used for Film-Cooled Nozzle}

The $91 \times 51$ computational grid employed for the filmcooled nozzle analysis is presented in Figure 12.

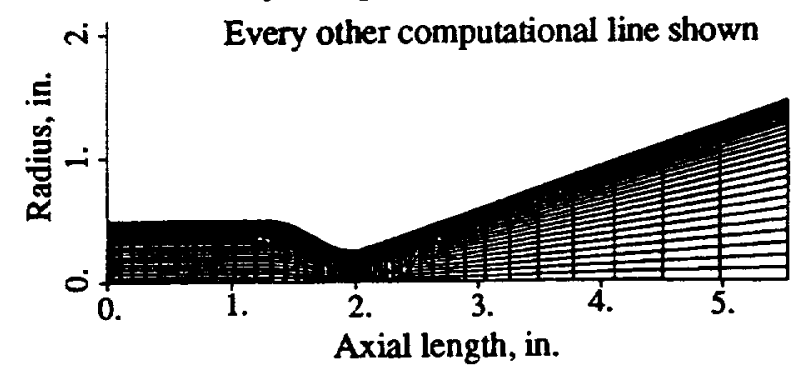

Fig. 12. 91X51 grid used for film-cooled nozzle study.

\section{Film-Cooled Nozzle Analysis Assumptions}

Three critical assumptions in the analysis of the 25 lbf, film-cooled rocket were made so that analytical results could be generated in an expedient manner. The critical assumptions were: (1) The flow was turbulent and could be reasonably modelled by an algebraic turbulence model, (2) the constituency of the core fluid flow of the nozzle was known, and (3) the radial and tangential velocity distribution at the nozzle inlet was zero for both the film and the core flow.

The flow was assumed to be turbulent in the film/core interaction region of the combustion chamber, based on: the Reynolds number of the hydrogen coolant in the sleeve was about 7000 , the Reynolds number of the core flow (based on the sleeve thickness) was about 5000, and that combustion creates an appreciable level of freestream turbulence.

Further down the engine, the flow may have experienced a significant amount of laminarization, both along the wall and in the mixing layer, as the flow was accelerated through the converging/diverging portion of the nozzle. This flowfield laminarization may not be adequately modelled by an algebraic turbulence model. However, since the nozzle was short, the overall shear stresses acting on the nozzle are relatively minor and contribute only to a small degradation of the total nozzle thrust. The model used in this analysis corresponded to a model applied by Gortler to obtain the proper variation of the turbulent viscosity in a mixing layer, with the near wall analysis being performed using the Baldwin-Lomax algebraic turbulence model. $^{16,17}$

For expediency, the assumption of a known chemical, thermal, and velocity distribution in the core-flow region needed to be made. As this was deemed to be a critical assumption in the analysis, two variations of the core flow inlet conditions were examined; one which assumed a fully-mixed core, and another which was based on temperature and species measurements of a similar injector/combustor. ${ }^{18}$

Because the hydrogen film was injected through a three-dimensional channel configuration before injection/ mixing with the core flow, it is certain that some distribution of radial and tangential velocity was present at the inlet region of the hydrogen film-cooled section. However, these velocity components were assumed to be of minor importance compared to the axial component of the velocity. Similarly, the oxygen and hydrogen propellants in the core region of the combustion chamber were injected radially and subjected to the effects of a blunt spark-plug ignitor. Under these conditions, the core flow would undoubtedly have some distribution of radial and tangential velocity for some distance downstream of the region where the propellants are injected. Adequate modelling of these conditions would require a three-dimensional analysis which was beyond the capabilities of the Tethys model. Instead, the sensitivity of nozzle performance to the degree of core mixing was examined. 


\section{Boundary Conditions for the Film-Cooled Nozzle}

Experimental values of the inlet mass flow rates, wall temperature, and exhaust pressure of the nozzle were used as boundary conditions in the analysis. To complete the boundary conditions, constant reference-plane characteristic relations were used at the inlet, exit, and nozzle centerline, with the exception that in the region around and downstream of the shock wave which strikes the centerline. A these boundary points, reflective boundary conditions were used.

Two different cases were analyzed, the variation being the assumed chemical profile at the inlet region of the core flow in the nozzle. One analysis assumed the flow to be fully mixed. The other assumed that the flow was stratified, as presented in Figure 13, and was based on temperature and species measurements in a similar injector. ${ }^{18}$

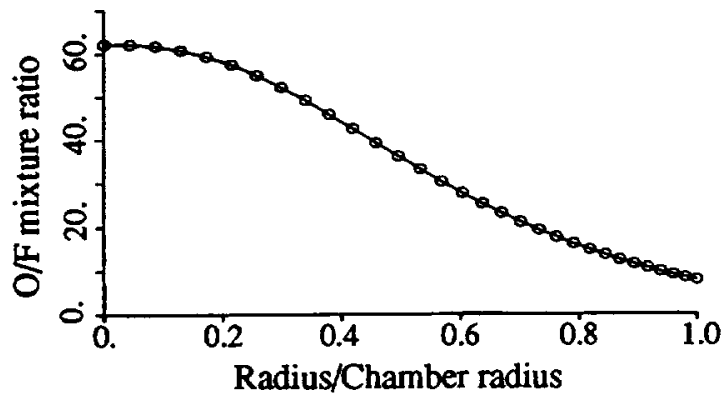

Fig. 13. Oxygen/hydrogen distribution used for the stratified core case.

\section{Mach Number Contour Predictions}

In Figure 14, the predicted Mach number distribution for the case of a fully-mixed core flow is presented. Here it is observed that a rather weak shock wave coalesces at the nozzle centerline and causes the Mach number to decrease from a value of around 3 to about 2.5. Also to be observed is the distorted nature of the Mach number profile in the highly supersonic region of the nozzle, where it is higher (at a given axial location) near the surface of the wall than the centerline. It is evident that the shock waves had a far greater affect near the nozzle centerline region than near the wall region. The Mach number distribution in the case of stratified flow has nearly the same qualitative properties as the fully-mixed case.

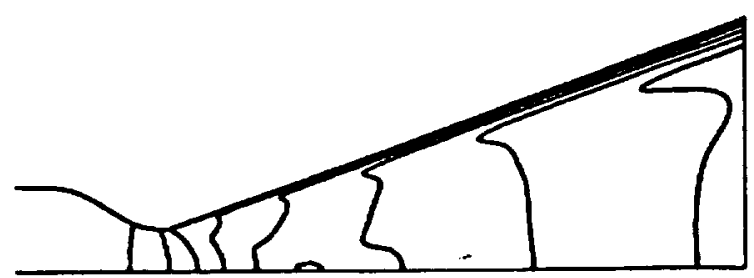

Fig. 14. Mach number contour predictions with the fully-mixed core case.

\section{Predicted Steam Mass Fraction Contours}

In Figure 15 and 16, a contour mapping of the mass fraction of steam $\left(\mathrm{H}_{2} \mathrm{O}\right)$ is shown for the fully-mixed core and the stratified core cases. In examining these two figures, numerous flow features become evident. One is that in both the fully-mixed and the stratified-core cases, fluid mixing is essentially non-existent in the supersonic region of the nozzle. This is entirely as expected, since the fluid convective speeds increase rapidly in the transonic portion of the nozzle, while the turbulence quantities tend to 'laminarize'. Another important observation is that the stratified flow-case exhibits a much lower mass fraction of steam in the core region of the flow throughout the nozzle. Since the creation of steam is associated with a large increase in thermal energy, a significantly higher performance can be expected from the fully-mixed core case. As will be shown later, this is exactly the situation.

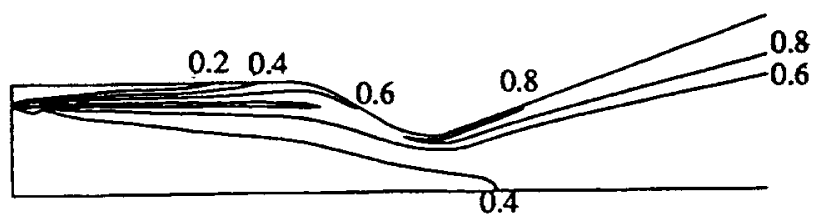

Fig. 15. Steam mass fraction predictions using the fully-mixed core assumption.

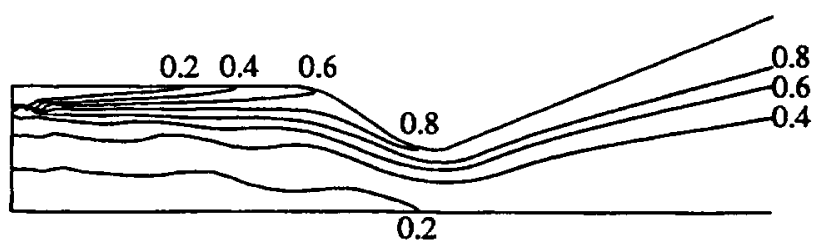

Fig. 16. Steam mass fraction predictions using the stratified core assumption.

\section{Predicted and Experimental Heat Transfer Rates}

Global measurements of wall heat-transfer rates were made. The predicted distribution of wall heat flux is shown in Figure 17 for the case of stratified flow, with the fullymixed case having a similar heat-flux profile but possessing a somewhat larger heat-flux peak. A noteworthy observation is that the peak in the nozzle heat flux is appreciably upstream of the nozzle throat. This peak heatflux location is well upstream of the location normally observed due to nozzle curvature. Based solely on nozzle curvature, the peak in heat flux would be expected to occur approximately 0.04 in. upstream of the throat. ${ }^{19}$ The profile seems to suggest injector streaking. The streaking probably occurs because the momentum of the hot-film core was significantly greater than that of the hydrogenfilm coolant, by about 20 times. The core flow thus has the tendency towards direct impingement onto the wall since the low momentum of the coolant has little ability to force the core flow to turn with the geometry. Consequently, the fluid streamlines become concentrated very near the wall of the nozzle. 


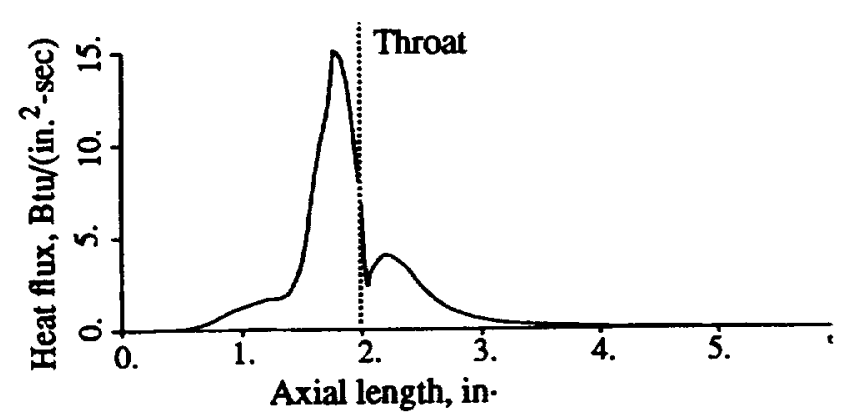

Fig. 17. Wall heat fluxes predicted for the film-cooled nozzle using the stratified core assumption.

Another noteworthy aspect of the heat-flux predictions shown in Figure 17 is the local minimum, followed by a local maximum that occurs just downstream of the throat. In fact, the sharp increase in heat flux corresponds precisely to the region where the geometric transition from the circular-arc throat to the conical divergence occurs.

The global heat-transfer measurements and predictions of heat transfer are presented in Table 4.

Table 4. Measured and predicted heat transfer.

\begin{tabular}{|l|c|}
\hline & Heat transfer, Btu/sec \\
\hline \hline Experiments & 23.6 \\
\hline Stratified flow analysis & 23.0 \\
\hline Fully mixed analysis & 31.5 \\
\hline
\end{tabular}

The stratified-flow analysis predicts heat transfer rates that are within $2.6 \%$ of experimental measurements. Given that the turbulence model was rather simplistic in nature and the turbulent Prandtl number was tailored to accurately reflect free-stream mixing conditions, a rather coarse, loosely packed grid was used, and the fact that the constituency of the stratified core itself was only modestly well defined, it is most likely that this high level of agreement between analysis and experiment is fortuitous. The predicted heat-transfer rates for the case of the fully-mixed core are substantially higher than experimental measurements and that predicted in the stratified-flow analysis.

\section{Predicted and Measured Performance Parameters}

In the case of this particular film-cooled nozzle analysis, the prediction of nozzle performance was especially difficult since the chemical composition of the core flow was not known and had to be assumed. Further, the mixing effects between the film and the fluid core were essential to predict specific impulse and characteristic velocity and would seem to depend heavily on the nature of the turbulence model. In light of this, the critical performance parameters of $I_{s p}, c^{*}$, and $C_{F}$ are compared for the analytical and experimental results of the two nozzle cases. The results, shown in Table 5, indicate that the flow may have been even more stratified than what was assumed in the analysis as the stratified-flow predictions are somewhat higher than experimental measurements. The analysis predicted a $6.4 \%$ higher specific impulse and a $5.9 \%$ higher characteristic velocity than was obtained experimentally. However, it should be noted that a different injector used in the test program yielded specific impulse and characteristic velocity measurements that were within $3 \%$ of predictions. Performance measurements for thrust coefficient are within $0.5 \%$ of predictions for the stratified-flow analysis case.

In general, the stratified-core predictions for engine performance are about $5 \%$ closer to the experimentally measured values than the fully-mixed core case. The exception is the nozzle vacuum thrust coefficient which is nearly the same in both analysis. Again, the accuracy of the Tethys model in predicting thrust coefficient and the relative insensitivity of this parameter with respect to flow stratification indicates that if the core flow had been more stratified than indicated in the analysis, it would have had little impact on the already very accurate thrust coefficient predictions.

Table 5. Comparison of predicted and measured filmcooled nozzle performance parameters.

\begin{tabular}{|c|c|c|c|}
\hline & Measured & Fully mixed & Stratified \\
\hline \hline $\mathrm{I}_{\mathrm{sp}}$ & 304.1 & 339.9 & 323.5 \\
\hline $\mathrm{c}^{*}$ & 5947. & 6599. & 6296. \\
\hline $\mathrm{C}_{\mathrm{F}}$ & 1.645 & 1.657 & 1.653 \\
\hline
\end{tabular}

\section{Transpiration Cooled Rocket Nozzle}

A hydrogen/oxygen transpiration-cooled rocket engine was tested at the NASA LeRC in the early 1970 's. ${ }^{20}$ The purpose of the program was to verify if hydrogen coolant could significantly reduce heat fluxes in the throat region of a rocket nozzle and to demonstrate if a new technique of creating a transpired region, via a series of fine platelet stacks, produced a reliable, efficient and economical means of transpiration cooling. Schematics of the baseline rocket engine and the transpiration-cooled spool piece section are shown in the Figures 18 and 19. The demonstration tests for hydrogen transpiration cooling were not performed on a conventional converging-diverging rocket nozzle but rather with a plug-and-spool nozzle, with the transpiration coolant being injected into the main stream of the exhaust gases only along the spool piece and limited to a region 0.5 inches in length ending at the throat. The overall length of the spool piece was 4 inches while the gap between the spool piece and the plug was 0.25 inches at the throat and 0.5 inches in the combustion chamber. The inside diameter of the spool piece was 2.6 inches.

The nominal operating pressure of the engine was 600 psia and the nominal oxygen/fuel mixture ratio was 6 . 


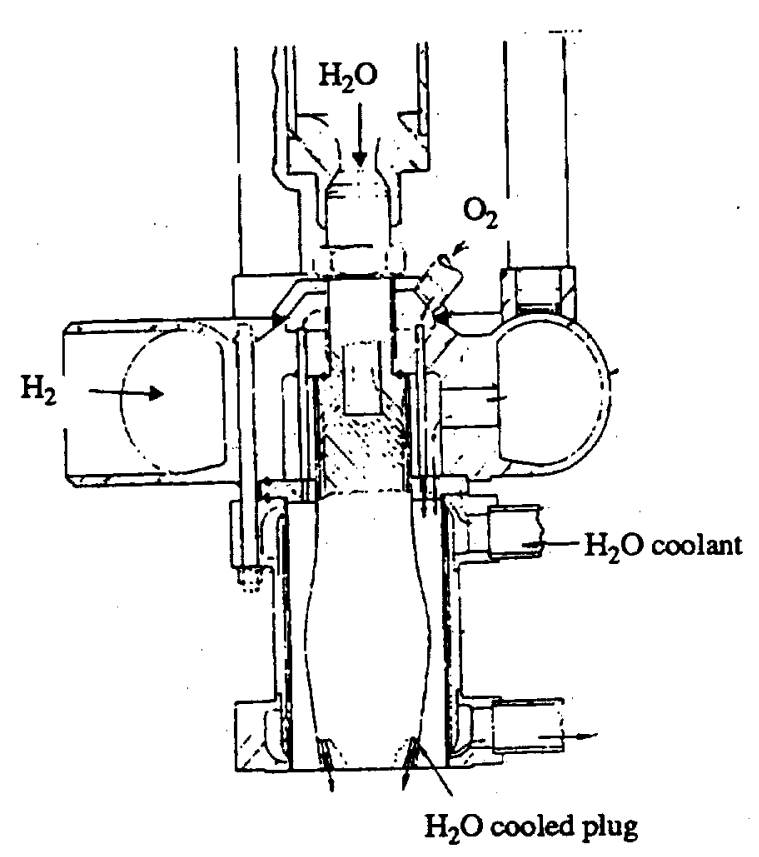

Fig. 18. Plug and spool rocket tested at NASA LeRC.

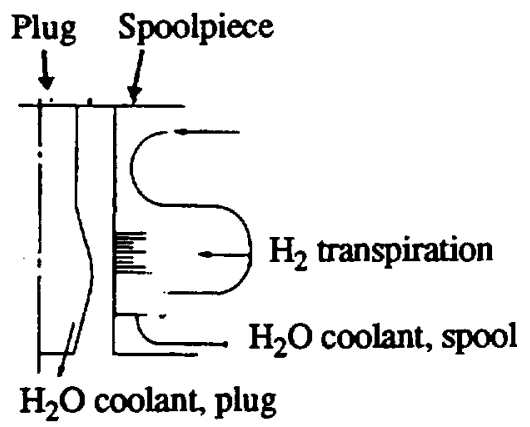

Fig. 19. Transpiration cooled spoolpiece section.

Several important assumptions were made with the Tethys code in modelling the flowfield of this engine. Because of the relatively incomplete nature of the experimental data reported, and the significant computational advantages, the hydrogen/oxygen propellant system was assumed to be comprised of a perfectly combusted mixture of steam and excess hydrogen. Furthermore, the temperature of the transpired coolant was presumed to be equal to the wall temperature of the copper platelet stack through which it flowed. While no direct temperature measurement of the fluid being injected was made, a heat-transfer analysis performed during the experimental program indicated that the wall temperatures may have been $300 \mathrm{R}$ hotter than the coolant fluid. However, an estimated temperature of the coolant fluid was used in the Tethys analysis to represent the wall temperature in the transpired section, with the reasoning that the $300 \mathrm{R}$ difference in temperature was far more critical to the change in enthalpy of the coolant than the conduction heat transfer. The temperature profile deduced from the experimental data and used in the Tethys analysis for the transpiration-cooled nozzle is shown in Figure 20.

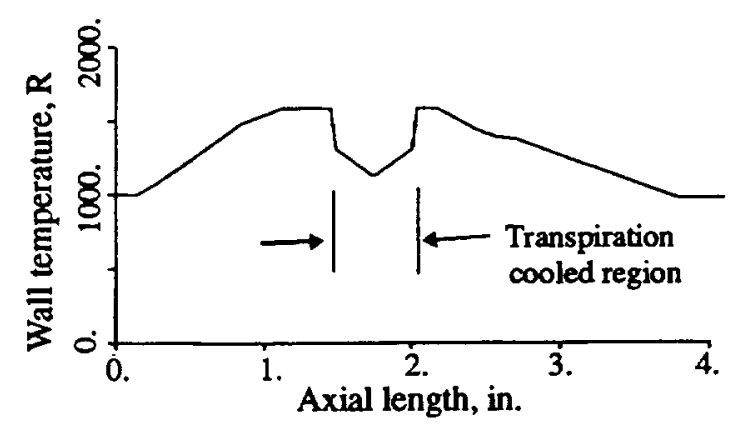

Fig. 20. Wall temperature distribution.

An additional consideration investigated was the roughness effect of the transpired surface on the flow stream. Because the transpired region represented a series of rather coarse and rough (a surface roughness of $12 \mathrm{mils}$ was measured) platelet stacks, a smooth-wall and a roughwall analysis was performed to evaluate the effect of this condition.

\section{Mass Flux Predictions}

The mass flow rate required to maintain the wall at the prescribed temperature shown in Figure 20 is a critical parameter. Because the mass flow that enters a transpired region may exit via diffusion (either ordinary or thermal) and advection, the relative importance of each is also of interest. In the figures that follow, the mass flux predictions for both the smooth-wall and the rough-wall analysis are presented.

In Figure 21, the predictions of mass flux in the transpiration-cooled section of the nozzle are presented for the two analysis cases along with the averaged mass flow rate measured in the experimental program. One significant result is that the mass flow rates of a smooth, transpirationcooled wall are appreciably lower than was experimentally observed. On the other hand, the rough-wall analysis appears to track the experimental mass fluxes rather well until reaching the center of the transpiration section. At the point where the prescribed wall temperature begins to increase (i.e., the center of the transpiration-cooled section), the mass injected into the fluid stream acts as a film coolant and serves to reduce the transpiration flow until reaching the edge of the transpiration-cooled region where the highly accelerating flow serves to dramatically increase coolant requirements, The extent to which this occurs may be overexaggerated because of the discontinuous nature of the adjoining boundary conditions. Similar trends are observed in the smooth-wall analysis but to a much lesser extent. Table 6 summarizes the differences between the observed and predicted transpiration mass flow rates in the plug-and-spool engine. Here it is observed that the smooth-wall prediction is nearly $1 / 2$ that of experimental measurements, while the rough-wall prediction is much closer to experimental results, and is only $13 \%$ lower than experimentally measured flow rates. 


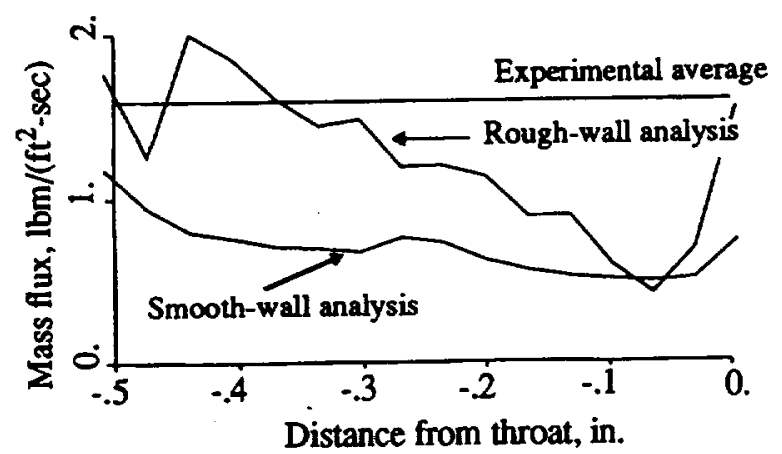

Fig. 21. Predicted and experimental mass fluxes.

Table 6. Total coolant flow rate requirements.

\begin{tabular}{|l|l|l|l|l|}
\hline \multirow{2}{*}{} & \multicolumn{2}{|c|}{ Analysis } & Exp. & \multirow{2}{*}{ Difference, \% } \\
\cline { 2 - 4 } & Smooth & Rough &.-- & \\
\hline \hline $\begin{array}{l}\text { Flow rate, } \\
\text { lbm/sec }\end{array}$ & 0.022 & 0.039 & 0.045 & $\begin{array}{l}\text { Smooth: }-51 . \\
\text { Rough: }-13 .\end{array}$ \\
\hline
\end{tabular}

The individual contributions of mass flux into the fluid stream are shown in Figures 22 and 23 for the smoothwalled and rough-walled cases, respectively.

Examination of the smooth-wall case shows many interesting features. The first is the importance of the Soret mass-flux term in both the solid-wall and transpirationcooled sections of the nozzle. As the term is always positive, the Soret term drives the lighter fluid (hydrogen) away from the wall and towards the mainstream of the exhaust gases. In the solid-wall regions of the flow, the positive Soret hydrogen flux term is balanced by the ordinary diffusion terms resulting in no net fiux. On the other hand, in the transpiration-cooled section of the engine, the ordinary diffusion flux is in the positive direction with the net result that all hydrogen mass flux terms, advective and diffusive, act to drive the hydrogen into the flow stream.

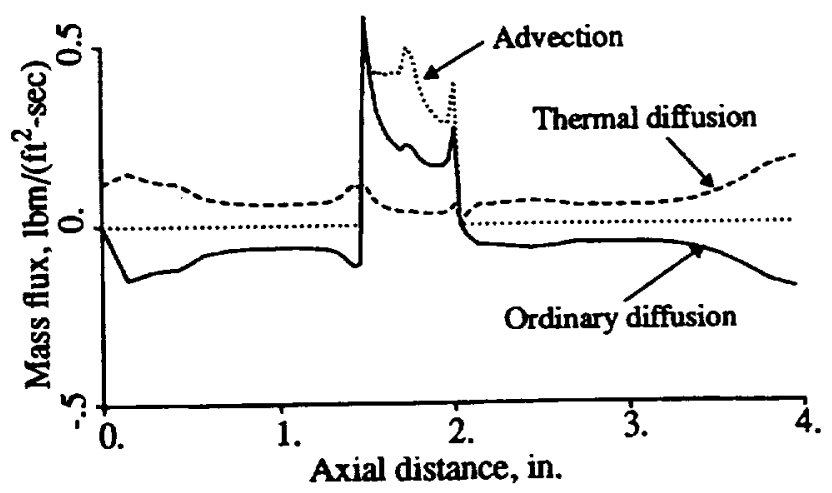

Fig. 22. Predicted hydrogen mass fluxes along the wall using a smooth-wall analysis.

The rough-wall case exhibits many of the same trends as the smooth-wall case with the exception that in the tran- spiration-cooled section of the engine the contributions of hydrogen mass flux as the result of ordinary and thermal diffusion are very small compared to the contributions of the advective and turbulent diffusion terms. This is to be expected as an extremely high level of surface roughness was used in the analysis.

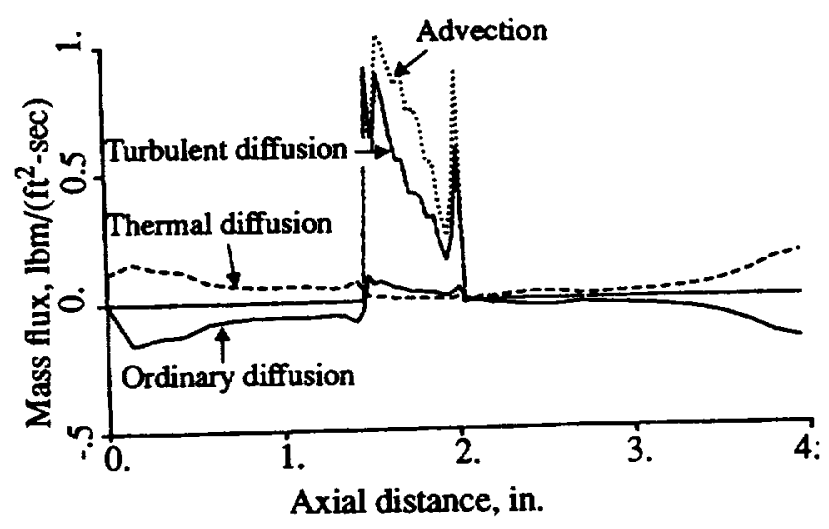

Fig. 23. Predicted hydrogen mass fluxes along the wall using a rough-wall analysis.

The individual contributions of diffusion heat-flux components into the fluid stream are shown in Figure 24 for the smooth-wall case. The results of the rough-wall case have qualitatively similar results. ${ }^{5}$ The heat transfer rates due to conduction are seen to vary dramatically throughout the nozzle. The conduction heat-transfer rate decays significantly in the transpiration-cooled section of the nozzle, being about $20 \mathrm{Btu} /\left(\mathrm{in} .^{2}\right.$-sec) just before the transpiration-cooled section and then decaying to less than $10 \mathrm{Btw} /\left(\mathrm{in}^{2}{ }^{2}\right.$-sec) in the transpiration-cooled section. The effect of this film cooling would probably be greater than suggested as the conduction heat flux would normally (i.e., if the wall were solid) increase by $50 \%$ in this region as the result of flow acceleration. 21

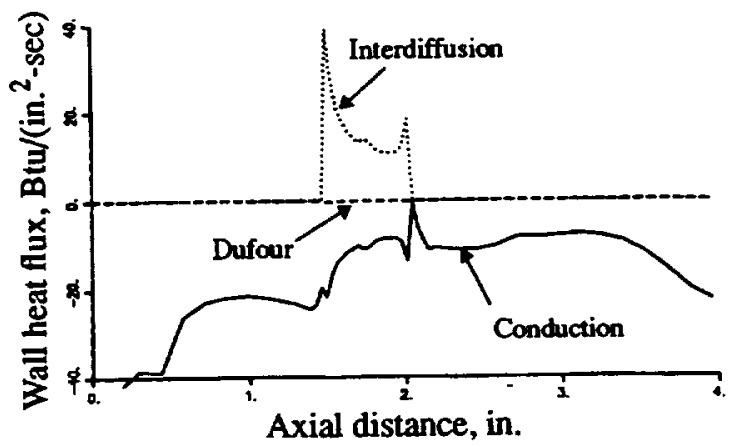

Fig. 24. Predicted heat flux into the exhaust gases using a smooth-wall analysis.

Unlike conduction, the flux of heat as the result of interdiffusional heat transfer is observed to be directed into the main stream of the flow. This is the result of the enthalpy of steam being negative at the prescribed wall temperatures.

A final observation to be made is that the flux of heat as the result of Dufour heat transfer is negligible. 


\section{Conclusions}

An advanced engineering tool has been developed for the analysis of chemical hydrogen/oxygen rocket engines. Demonstration cases of a 1030:1 area ratio nozzle, a filmcooled rocket engine, and a transpiration-cooled rocket engine, were analyzed. In the demonstration cases examined, the model predicted thrust coefficient within $0.2 \%$ to $0.5 \%$ of experimental measurements, which was well within experimental uncertainties of the test data. Heatflux predictions also agree well with experimentally measured values. Among some of its unique attributes, the model includes the effects of Soret mass transfer and Dufour heat transfer, where the Soret mass transfer term was shown to play an important role in the mass-flux contribution of a transpiration-cooled nozzle and in establishing the species mass fraction along the wall of a solidwalled engine. Conversely, the Dufour heat transfer term was shown to be negligible.

\section{References}

1. Towne, Charles E., Schwab, John R., and Bui, Trong T., Proteus Two-Dimensional Navier-Stokes Computer Code-Version 2.0 Volume 1-Analysis Description, NASA TM-106336, 1993.

2. Towne, Charles E., Schwab, John R., and Bui, Trong T., Proteus Two-Dimensional Navier-Stokes Computer Code-Version 2.0 Volume 2-User's Guide, NASA TM-106336, 1993.

3. Towne, Charles E., Schwab, John R., and Bui, Trong T., Proteus Two-Dimensional Navier-Stokes Computer Code-Version 2.0 Volume 3-Programmer's Reference, NASA TM-106336, 1993.

4. Bird, R. Byron, Stewart, Warren E., and Lightfoot, Edwin N., Transport Phenomena, John Wiley and Sons, 1960.

5. Kacynski, Kenneth J., Calculation of Propulsive Nozzle Flowfields in Multidiffusing Chemically Reacting Environments, Ph.D. Thesis, Purdue University, 1994.

6. Pavli, Albert J., Kacynski, Kenneth J., and Smith, Tamara A., Experimental Thrust Performance of a High-Area-Ratio Rocket Nozzle, NASA TP-2720, 1987.

7. Kacynski, Kenneth J., Pavli, Albert J., and Smith, Tamara A., Experimental Evaluation of Heat Transfer on a 1030:1 Area Ratio Rocket Nozzle, NASA TP-2726, 1987.

8. Smith, Tamara A., Pavli, Abert J., and Kacynski, Kenneth J., Comparison of Theoretical and Experimental Thrust Performance of a 1030:1 Area Ratio Rocket Nozzle at a Chamber Pressure of $2413 \mathrm{kN} /$ $\mathrm{m}^{2}$ (350 psia), NASA TP-2725, 1987.

9. Smith, Tamara A., Boundary Layer Development as a Function of Chamber Pressure in the NASA Lewis 1030:1 Area Ratio Rocket Nozzle, AIAA-88-3301, 1988.
10. Pauley, L. L., and Dagher, S. N., A Numerical Investigation of Supersonic Nozzle Boundary Layer Transition, AIAA 91-3559, 1991.

11. Nickerson, Gary R., Comparison and Evaluation of Computer Results for Rocket Engine Performance Prediction, NASA Contract NAS 7-443, 1967.

12. Nickerson, G. R., Coats, D. E., and Dang, L. D., Engineering and Programming Manual: TwoDimensional Kinetics Reference Computer Program (TDK). (SN-63, Software and Engineering Associates, NASA Contract NAS8-35931.) NASA CR-178628, 1985.

13. Kim, S., Numerical Study of High-Area Ratio H2/ O2 Rocket Nozzles, AIAA-91-2434, 1991.

14. Morren, Sybil Huang, Myers, Roger M., Benko, Stephen E., Arrington, Lynn A., and Reed, Brian D., A Laboratory Model of a Hydrogen/Oxygen Engine for Combustion and Nozzle Studies, AIAA-93-1825, 1993.

15. Arrington, Lynn A., and Reed, Brian D., Performance Comparison of Axisymmetric and ThreeDimensional Hydrogen Film Coolant Injection in a 110N Hydrogen/Oxygen Rocket, AIAA-92$3390,1992$.

16. Gortler, H., Z. Angew. Math. Mech., vol. 22, pp. 244-254, 1939.

17. Baldwin, B. S., and Lomax, H., Thin Layer Approximation and Algebraic Model for Separated Turbulent Flows, AIAA-78-257, 1978.

18. de Groot, W. A., and Tsuei, H. H., Gaseous Hydrogen/Oxygen Performance Characterization, NASA CR-194464, 1994.

19. Zucrow, Maurice J., and Hoffman Joe D., Gas Dynamics, Volume II, John Wiley and Sons, 1977.

20. Valler, H. W., Performance of a Transpiration Cooled Rocket Thrust Chamber, NASA CR$159742,1979$.

21. Quentmeyer, Richard J., Hot-Gas-Side Heart Transfer Characteristics of Subscale, Plug-Nozzle Rocket Calorimeter Chamber, NASA TP-3380, 1993. 
Public reporting burden for this collection of information is estimated to average 1 hour per response, including the time for reviewing instructions, searching existing data sources, Pathering and maintaining the data needed, and completing and reviewing the collection of information. Send comments regarding this burden estimate or any other aspect of this collection of information including suggestions for reducing this burden, to Washington Headquarters Services, Directorate for Information Operations and Reports, 1215 Jefferson Davis Highway, Suite 1204. Arlington, VA 22202-4302, and to the Office of Management and Budget, Paperwork Reduction Project (0704-0188), Washington, DC 20503.

\begin{tabular}{|l|c|c|c|}
\hline 1. AGENCY USE ONLY (Leave blank) & $\begin{array}{c}\text { 2. REPORT DATE } \\
\text { May } 1994\end{array}$ & $\begin{array}{r}\text { 3. REPORT TYPE AND DATES COVERED } \\
\text { Technical Memorandum }\end{array}$ \\
\hline
\end{tabular}

\section{TITLE AND SUBTITLE}

The Prediction of Nozzle Performance and Heat Transfer in Hydrogen/Oxygen

Rocket Engines with Transpiration Cooling, Film Cooling, and High Area Ratios

\section{AUTHOR(S)}

Kenneth J. Kacynski and Joe D. Hoffman
WU-232-01-0A

\section{PERFORMING ORGANIZATION NAME(S) AND ADDRESS(ES)}

National Aeronautics and Space Administration

Lewis Research Center

Cleveland, Ohio 44135-3191

\section{SPONSORING/MONITORING AGENCY NAME(S) AND ADDRESS(ES)}

National Aeronautics and Space Administration

Washington, D.C. 20546-0001
8. PERFoRMING ORGANIZATION REPORT NUMBER

E-8902
10. SPONSORINGMONITORING AGENCY REPORT NUMBER

NASA TM-106617

AIAA-94-2757

\section{SUPPLEMENTARY NOTES}

Prepared for the 30th Joint Propulsion Conference cosponsored by the AIAA, ASME, SAE, and ASEE, Indianapolis, Indiana, June 27-29, 1994. Kenneth J. Kacynski, NASA Lewis Research Center, and Joe D. Hoffman, Purdue University, West Lafayette, Indiana 47906. Responsible person, Kenneth J. Kacynski, organization code 5320, (216) 433-7497.

12a. DISTRIBUTIONAVAILABILITY STATEMENT

12b. DISTRIBUTION CODE

Unclassified - Unlimited

Subject Categories 34 and 20

\section{ABSTRACT (Maximum 200 words)}

An advanced engineering computational model has been developed to aid in the analysis of chemical rocket engines. The complete multispecies, chemically reacting and diffusing Navier-Stokes equations are modelled, including the Soret thermal diffusion and Dufour energy transfer terms. Demonstration cases are presented for a 1030:1 area ratio nozzle, a $25 \mathrm{lbf}$ film-cooled nozzle, and a transpiration-cooled plug-and-spool rocket engine. The results indicate that the thrust coefficient predictions of the 1030:1 nozzle and the film-cooled nozzle are within 0.2 to 0.5 percent, respectively, of experimental measurements. Further, the model's predictions agree very well with the heat transfer measurements made in all of the nozzle test cases. It is demonstrated that thermal diffusion has a significant effect on the predicted mass fraction of hydrogen along the wall of the nozzle and was shown to represent a significant fraction of the diffusion fluxes occurring in the transpiration-cooled rocket engine.

\section{SUBJECT TERMS}

Nozzle flow fields; Multidiffusing; Chemically reacting; Film cooling;

Transpiration cooling; Thermal diffusion

17. SECURITY CLASSIFICATION
OF REPORT
Unclassified

NSN 7540-01-280-5500
18. SECURITY CLASSIFICATION OF THIS PAGE

Unclassified
19. SECUAITY CLASSIFICATION OF ABSTRACT Unclassified
15. NUMBER OF PAGES

13

16. PRICE CODE

$$
\mathrm{A03}
$$

